\title{
Social Media Sustainability Communication: An Analysis of Firm Behaviour and Stakeholder Responses
}

\author{
Ashish Kumar Jha ${ }^{1}$ D Nishant Kumar Verma ${ }^{2}$ \\ Accepted: 4 February 2022 / Published online: 2 March 2022 \\ (c) The Author(s) 2022
}

\begin{abstract}
Social media communication, and its impact on individuals and firms, is becoming increasingly important in today's age. Firms are utilizing social media channels for communicating their sustainability-related initiatives. The role of social media as a mode for sustainability-related communication by firms has not been widely analyzed in the extant information systems literature. Given the increasingly important role of social media for information diffusion as well as increasing awareness for sustainability practices, this is a critical area of research. In this paper, we use an analytic model to theorize, coupled with empirical analysis to test the impact of firms' sustainability practices. We have validated our proposed hypotheses using an empirical model based on panel data of firms' sustainability performance and their Twitter communication over a 3-year period. Through our unique mixed-method study, we add additional methodological rigour to extant social media-based research in the information systems domain. Our research has significant theoretical and managerial significance as we identify how firms utilize social media for sustainabilityrelated communication and its corresponding impact on customer response. Our research provides actionable insights for policymakers, firms as well as investors and consumers on understanding and managing sustainability-related communications on social media.
\end{abstract}

Keywords Social media communication $\cdot$ Sustainability $\cdot$ Analytical model $\cdot$ Twitter

"The post-illusion era is characterized by transparency and the requirement to walk the talktwo values that are fundamental to sustainability too."

\section{Introduction}

Many recent studies have shown the growing importance of social media among firms to communicate a vast variety of information to their stakeholders (Benitez et al., 2020; Di Gangi et al., 2018). These include communication on noncore firm activities like their CSR initiatives (Benitez et al.,

Ashish Kumar Jha

akjha@tcd.ie

Nishant Kumar Verma

nishant.verma@iimb.ac.in

Trinity College Dublin, Dublin, Ireland

2 Indian Institute of Management Bangalore, Bengaluru, India
2020) or managing social enterprises (Tung \& Jordann, 2017). This is due to the growing interest among individuals to access information through social media. It is noted that about half of the US adults often get their news from social media channels (Pew Research Centre, 2021). Hence, it does not come as a surprise that GlobalWebindex found social media to be the most preferred channel among eco-consumers to access information on firms' sustainability initiatives (Valentine, 2019).

Extant research in the domain of information systems has also studied the role of social media in the dissemination and impact of sustainability-related communication from both political as well as corporate leaders (Grover et al., 2019, 2021). To an extent, existing literature has analyzed the propensity and impact of sustainability linked social media communication (Kushwaha et al., 2021; Richardson et al., 2016). However, sustainability-related communication by large corporations and its impact on consumers remains an understudied area. In this study, we aim to study the impact of business firms' social media communication on their target audience. 
Specifically, we answer the following research questions:

1) Does communication-related to sustainability initiatives generate firm value?

2) Do sustainability sensitive stakeholders make choices based on the sustainability information fetched from their preferred information channels.

3) Under what conditions do firms behave proportionately or disproportionately in communicating their sustainability investment initiatives?

4) Do manufacturing firms communicate differently than non-manufacturing firms?

We use an analytical model to theorize our research context and arrive at testable hypotheses. We then test the hypotheses empirically using the data collected through robust databases. The first two research questions attempt to test whether the communication made by firms around their sustainability initiatives is influencing their stakeholders' decisions and translating into enhanced firm value.

Whereas the first two research questions test the impact of firm communication on stakeholder behaviour, the second set of questions theorizes and test firm communication behaviour. The second set of questions become increasingly important in the context of a social media dominant society. Past trends have shown that even reputed firms overstate or misinform consumers about their sustainability initiatives. In February 2020, 'Ben \& Jerry®', a firm owned by Unilever has withdrew misleading labels from their products after being sued twice for deceiving consumers. The firm had used its social media handles to flaunt its "caring dairy" program. However, Unilever argued in the court of law that these claims are "not fact based promises" (Shooster, 2020). In another development in February 2020, Australian cosmetics brand 'Mecca ${ }^{\circledR}$ ' claimed over social media that all its products are 'cruelty-free', leading to consumers and industry watchdog Estee Laundry calling out the firm over social media (Tassios, 2020).

On one hand, we observe questionable firm sustainability behaviour, and on the other hand, we find consumers' general distrust against information from social media and review platforms (Kim et al., 2019). Therefore, it is important to study how much importance consumers give to a firm's sustainability-oriented social media posts and how do firms utilize this channel for sustainability communication.

We develop an analytical model to theorize a firm's sustainability investment and communication behaviour. From a theoretical modelling perspective, our paper makes a novel attempt at modelling demand endogenously as a function of a firm's actual effort and the corresponding communication effort. Unlike the existing models in the sustainability literature, this is the first paper to simultaneously model a firm's sustainability investment efforts and the corresponding communication efforts as the key decision variables.

We also test our model's validity using a detailed empirical model based on financial and social media data of S\&P 500 firms. The empirical validation of the theoretical model through panel data of sustainability and social media communication data proves that, a.) social media communication about sustainability drives consumers response towards firms, thereby generating firm value and $b$.) formal sustainability reporting drives investors response. We also establish empirically that manufacturing and non-manufacturing firms have differential social media-based sustainability communication intensity. Further, we find that consumers may not care or be able to differentiate between manufacturing and non-manufacturing firms, investors certainly do.

\section{Literature Review}

Given the focus of our work on social media communication, we restrict ourselves to the literature around social media and firm communication to establish the research gap and highlight the significance of our work.

\subsection{Firm Communication on Social Media}

Though social media started as a medium to connect individuals, it has quickly evolved into an all-encompassing medium of communication (Chen et al., 2015; Schetgen et al., 2020). At the individual level, social media has been used to connect and discuss both mundane and socially relevant topics simultaneously (Kushwaha et al., 2020a). Social Media websites like Twitter and Facebook are credited with fast information diffusion in a wide pool of individuals (Chung et al., 2020a; Kushwaha et al., 2020b). The adoption of social media has also led to enhanced use of these platforms by corporates as well. With professional social networks like LinkedIn ${ }^{\circledR}$ as well as microblogging platforms like Twitter ${ }^{\circledR}$ becoming an increasingly important forms of connecting users to firms, they have emerged as one of the most important platforms for corporate communication (Huang et al., 2019). Firms actively use social media to communicate with their consumers and spread their messages or brand information (Hu et al., 2019). Kushwaha et al. (2020c) studied the enhanced role of social media based chatbots by firms to communicate with their customers about their products. The impact of social media for firm-specific communication can be gauged from the fact that as early as 2013 , over $66 \%$ of fortune 500 firms were engaged in corporate communication through these channels (Heggestuen \& Danova, 2013).

The rise of social network platforms over these years has had a profound impact on how firms engage with various 
stakeholders (Chen et al., 2015). Previous studies have identified that there are two kinds of social media content, user generated content (UGC) and firm generated/promoted content (FGC) that can impact either user behaviour or a firm's value and sales (Chung et al., 2020). Numerous pieces of research in extant literature have studied and established the impact of user generated content on social media platforms and blogs on user behaviour. For instance, Xie and Lee (2015) have established that both earned as well as owned exposure of firms on social media lead to a positive impact on the consumer's purchase likelihood. Extant research also finds the impact of user generated content on influencing future user review behaviour (Jha \& Shah, 2019)and review credibility (Jha \& Shah, 2021). However, a close study of extant literature also informs us that there are only a few that analyse the impact of user or firm generated content on the firm value (Chung et al., 2020). While a lot of studies have established the impact of non-firm controlled social media communication on firm value (for instance see (Deng et al., 2018)), very few studies have studied impact of firm controlled social media communication on firm value (Chung et al., 2020). In this study we wish to analyse the impact of not just any firm controlled social media communication on firm's performance but a more specific type of communication i.e. sustainability specific communication. Figure 1 categorises the various studies conducted within social media communication literature.

\subsection{Sustainability Related Communication}

Social media based sustainability communication is considered to be a form of brand communication that strengthens firms' corporate image that is inextricably linked to their performance and valuation (Voorveld, 2019) (some example tweets from our dataset is made available in Sect. 4.2). The research around sustainability initiatives and corporate communication through social media is very limited. Primarily two streams have evolved, with one focusing on the perspective of the firm and the other on that of the consumers. Research around firms' perspective has dealt with questions such as a.) what kind of firms are communicating more through social media (Reilly \& Hynan, 2014), b.) What type of content is being communicated (Amin et al., 2021; Gómez-Carrasco et al., 2021) What is impact of firms' social media sustainability communication on public responses (Fraustino \& ConnollyAhern, 2015; Saxton et al., 2019) and on their overall sustainability rating (Balasubramanian et al., 2020), and d.) Is social media stakeholder engagement an effective way of defining the contents of official sustainability reporting (Manetti \& Bellucci, 2016). From the consumers perspective, some research (Minton et al., 2012) has delved into understanding how do consumers' own sustainability practices change with the increased social media marketing on sustainability or in the domain of methodological research to understand consumer expectations as communicated through social media (Wu et al., 2020) or the potential impact of social-media in reducing greenwashing (Lyon \& Montgomery, 2013).

However, to the best of our knowledge, there has been no paper to study if the sustainability sensitive stakeholders are indeed making their decisions based on the information received through social media, which is widely touted as the communication medium of choice in these times, and therefore, in turn, are generating value for the firm (Please refer to Fig. 1). In that sense, our paper is the first to study the relationship between sustainability communication and firm value.
Fig. 1 Classifying the studies examining social media communication

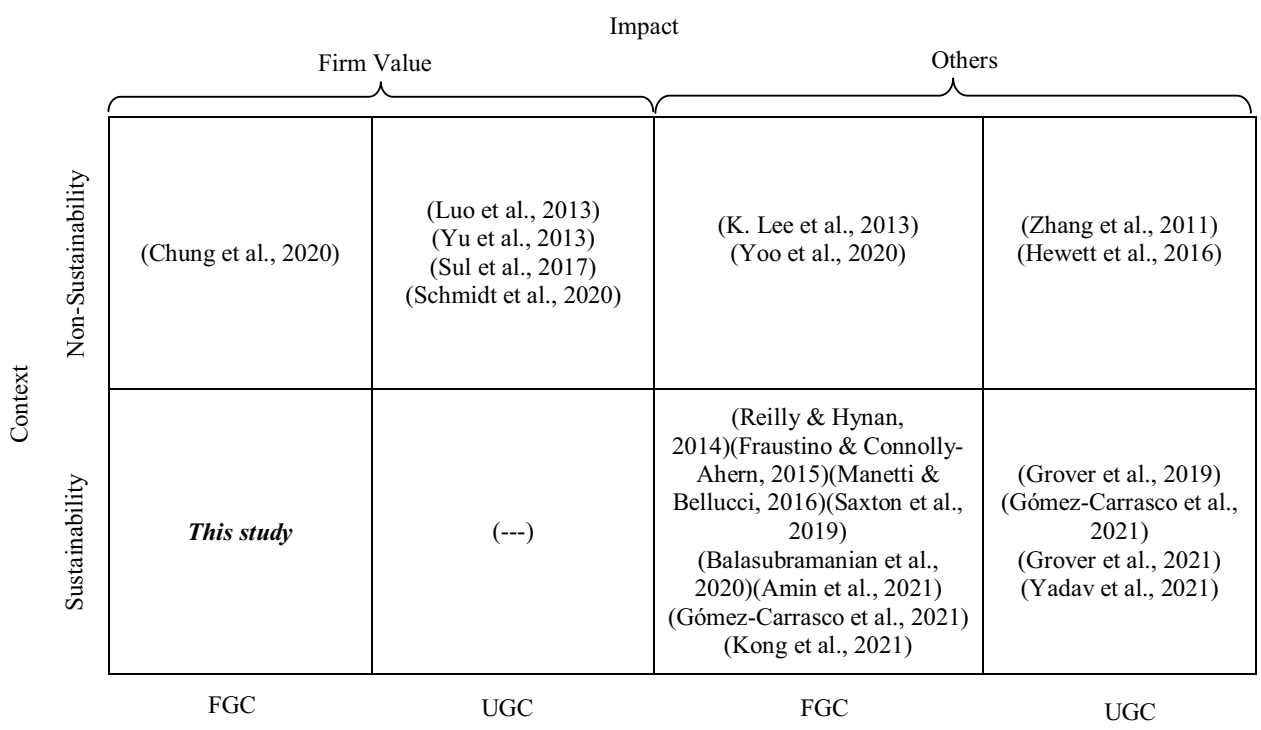




\section{Theoretical Background and Analytical model}

Before we develop the analytical model to come up with theoretically derived and empirically testable propositions, we delve into the theoretical argumentation behind the specific research questions that we intend to answer through our model.

\subsection{Firm Communication Behaviour and Stakeholder Response}

We start with the discussion around our first key research question, under what conditions do firms behave proportionately or disproportionately in communicating their sustainability investment initiatives?

Although firms of all kinds and nature are attempting to become more environmentally sensitive and sustainable, it is a fact that firms in many industries have an ecological footprint owing to the nature of their activities (Esfahbodi et al., 2016). Firms in industries such as mining, non-renewable energy, transportation, manufacturing etc. have the potential to cause huge damage to the environment. Even with the society attempting to move away from products that lead to environmental degradation, total independence from such industries is still a long way off and hence the industries remain active (Esfahbodi et al., 2016). The very nature of the activities in such industries leads to a situation where they have the maximum need to go green but the cost of going green is very high (Hong et al., 2019). This is in contrast to the non-manufacturing firms where the cost of sustainability initiatives is not as high as the manufacturing firms which requires costly initiatives linked to their core operations. On the other hand cost of sustainability communication (such as over social media) is not sensitive to any particular industry/ sector. Therefore, we expect the differential between a firm's actual sustainability initiatives and its corresponding communication over social media to be higher when the differential between the firm's average cost of actual initiatives and the cost of communication is more, i.e., we expect the differential to be more for manufacturing firms than non-manufacturing firms.

Our second key research question is, does communication related to sustainability initiatives generate firm value?, i.e., are stakeholders (consumers and investors) making their firm related decision/choice based on the firm's social media sustainability communication?.

From the consumer's perspective, sustainability has high importance. Anecdotal, as well as scientific evidence, points to the fact that ceteris paribus consumers prefer products of firms with a higher sustainability quotient (Bangsa \& Schlegelmilch, 2020). The important question though remains that how consumers identify which firms are more sustainable than others. Various mechanisms have been devised to promote the sustainable activities of firms. These include sustainability reports released by the firms themselves, third-party sustainability audits, rankings and reports as well as advertisement and communication campaigns run by firms (Herzig \& Schaltegger, 2006). In this context, it needs to be mentioned that consumers have a limited line of sight to the firm. This is because of the cognitive load of being involved with multiple brands in day to day life simultaneously (Fox et al., 2015). While consumers appreciate and want firms to be sustainable, they do not have the time or resources to individually track and verify the efforts being put by firms in this exercise (Fox et al., 2015). It is for these groups of stakeholders that communication, especially easily digestible communication, becomes essential (Fischer et al., 2016). Firms regularly promote and communicate to consumers their values and activities so that consumers are in the know of their efforts. This includes their social activities, sustainable activities, governance or other activities. Traditionally a lot of this communication has happened through television advertisements and print advertisements. However, the rise of social media channels like Facebook and Twitter has changed the game. Due to their wide reach and fast pace of communication, these mediums are often described as a medium of choice for consumers to interact with firms and get information on firms (Gomez et al., 2019). Therefore, we expect consumers of the firm that regularly communicate over social media about sustainability in general and related initiatives, in particular, to make favourable-to-firm decisions more frequently (thereby generating higher firm value) than consumers of the firm that communicates less over social media.

In the next sub-section, we establish theoretical underpinnings using an analytical model. Subsequently, we test our theory and the corresponding hypothesis using panel data of firms' sustainability performance and their Twitter communication over a 3-year period.

\subsection{Analytical Model}

Extant research has attempted to study the relationship between sustainability activities and consumer demand through various theoretical models (Zhu \& He, 2017). In this regard, different theoretical papers have been developed that have modeled consumer demand such that it increases as the sustainability efforts made by a firm increases, often called as green sensitive consumer market. Though modeling demand endogenously as a function of effort has been there 
for a while with Corbett and DeCroix (2001) taking demand as a function of effort exerted by both the firms involved in a business transaction. The literature around analytical models considering sustainability sensitive demand model is rather recent. Most of such papers are from operations management field exploring various aspects related to the supply chain dynamics. In their work, Ghosh and Shah (2012) studied apparel supply chain while modelling the sustainability sensitive consumer demand model. Zhu et al. (2017) studied design issues for green products under various scenarios of competition, whereas Yenipazarli (2017) study the implications of pushing eco-efficient innovation in supply chains. Raj et al. (2018) consider a supply chain scenario where the supplier is responsible for product greening whereas the buyer accounts for social responsibility.

The stated assumption in all these papers is that the consumers are assumed to be sustainability sensitive. However, another important unstated/underlying assumption made is that the consumers are seeking and in fact are aware of the actual sustainability investments/initiative taken by the firms. As we know consumers are an important organizational stakeholder just like the shareholders. However, it is reasonably unlikely that the consumers are seeking and fetching information regarding a firm's sustainability efforts through the formal channels such as annual/sustainability reports published. On the contrary, unlike shareholders, it is reasonable to assume that the consumers are getting informed about the sustainability intent and initiatives through the firm's more informal communication channels such as Twitter and Facebook. As stated in the preceding sections, the larger aim of this work is to study how firms behave under such circumstances. Through the theoretical model, we first aim to study the nature of optimal decisionmaking process for a firm which intends to impress their consumers through their sustainability efforts while still be able to maximize its profit.

We consider a firm selling its product/service to its consumers. Consumers are assumed to be sensitive towards price, actual sustainability investment made by the firm, and social media sustainability communication placed by the firm. In this regard, we consider a linear demand model as given below:

$d=a-b p+\alpha \theta+\beta i \eta$

Here, $a$ represents the market potential of the firm. ' $b$ ' represents the consumer sensitivity towards price $(p)$. As stated earlier, we assume consumers of the firm to be sustainability sensitive. Therefore, we assume a linear positive relation between the firm's demand $(d)$ and the sustainability efforts $(\theta a n d \eta)$. Here, $\theta$ represents the firm's effort towards actual sustainability investment and $\eta$ represents the firm's effort towards communicating their initiatives. The adoption of linear demand model enables us to get more interpretable results without losing any insights. Moreover, such a linear demand model with price and non-price variables (such as service/quality efforts) has been considered in operations management, decision sciences and marketing literature (Lee \& Staelin, 1997; Savaskan et al., 2004; Tsay \& Agrawal, 2000). $\alpha$ and $\beta$ represents the consumer sensitivity towards firm's sustainability investment and its' social media communication on sustainability respectively. All the other factors affecting the demand are kept constant, i.e., ceteris paribus we intend to study the impact of sustainability efforts $(\theta$ and $\eta)$.

Another aspect is the firms' interaction with their consumers. Firms can use social media like a traditional media source for one-way communication of their policies and practices or a two way street to interact with consumers. As an interactive medium, consumers expect firms to listen and talk to them on social media platforms (Chahine \& Malhotra, 2018). Firms with a history of social media interaction with their consumers build up a more active following on social media where they see a higher average retweets and likes (Chahine \& Malhotra, 2018). Factor ' $i$ ' represents social media interaction capability of the firm which moderates the relation between the demand and the firm's sustainability communication efforts.

The cost function for the firm is given below:

Cost $=I_{1} \theta^{2}+I_{2} \eta^{2}$

The cost function is quadratic in nature, i.e., it increases nonlinearly in the sustainability efforts $(\theta$ and $\eta$ ) put in by the firm. The nonlinear relation implies that the cost of putting an additional unit of sustainability effort $(\theta$ or $\eta)$ is higher for a high base effort level than for a low base effort level. The nonlinear (convex) assumption is in line with the argument often put forth that firms try to implement "low hanging fruits" initiatives first than the more complex initiatives (Porter $\&$ der Linde, 2011). $I_{1} \& I_{2}$ represent the investment cost factors associated with the respective sustainability efforts. We further assume that $I_{1}>I_{2}$. This is a reasonable assumption as the cost incurred for communicating firm's sustainability efforts through social media is lower (by a significant margin) in comparison to the cost incurred for the real time sustainability investment.

Various definitions of the variables and the parameters of the model are provided in Table 1.

Given the demand equation for the firm, it tries to maximize the profit as expressed below:

Maximize Proft $=(a-b p+\alpha \theta+\beta i \eta)(p-c)-I_{1} \theta^{2}-I_{2} \eta^{2}$

Next, we try to analyze the optimization problem faced by the firm. The basic results in this regard are the optimal 
Table 1 Definition of variables used in the analytical model

\begin{tabular}{ll}
\hline$d$ & Demand for the firm's product/service \\
$a$ & Market Potential \\
$p$ & Per unit price for the product/service \\
$c$ & Per unit cost for the product/service \\
$\alpha$ & Consumer sensitivity towards the firm's actual sustainability investment \\
$\theta$ & Quantum of sustainability investment made by the firm \\
$\beta$ & Consumer sensitivity towards the firm's social media communication \\
$0 \leq i \leq 1$ & on sustainability \\
$\eta$ & Social media consumer interaction capability of the firm \\
$I_{1}$ & Quantum of sustainability communication made by the firm \\
$I_{2}$ & Sustainability investment cost factor
\end{tabular}

variable expressions that maximize profit for the firm. All the proofs for the propositions and the data used for numerical analysis is relegated to appendix.

Proposition 1 The objective function as expressed above is strictly jointly concave in $\mathrm{p}, \theta$, and $\eta$. Solving for the optimal $\mathrm{p}^{*}, \theta^{*}, \& \eta^{*}$ that maximizes the firm's profit, we get the following:

\begin{tabular}{ll}
\hline$p^{*}$ & $\frac{2 I_{1} I_{2}(a+b c)-c\left(\alpha^{2} I_{2}+\beta^{2} i^{2} I_{1}\right)}{4 b I_{1} I_{2}-\left(\alpha^{2} I_{2}+\beta^{2} i^{2} I_{1}\right)}$ \\
$\theta^{*}$ & $\frac{\alpha I_{2}(a-b c)}{4 b I_{1} I_{2}-\left(\alpha^{2} I_{2}+\beta^{2} i^{2} I_{1}\right)}$ \\
$\eta^{*}$ & $\frac{\beta i I_{1}(a-b c)}{4 b I_{1} I_{2}-\left(\alpha^{2} I_{2}+\beta^{2} i^{2} I_{1}\right)}$ \\
\hline
\end{tabular}

Lemma 1 The impact of key parameters on optimal sustainability efforts, $\theta^{*}$ and $\eta^{*}$ is as follows: $\frac{\partial \theta^{*}}{\partial I_{1}}<0, \frac{\partial \eta^{*}}{\partial I_{2}}<0, \frac{\partial \eta^{*}}{\partial i}>0$

Proposition 1 establishes the baseline relationship between firm's profit and its actions in terms of sustainability efforts and its communication. We find that the optimal sustainability efforts $\theta^{*}$ and $\eta^{*}$ decreases as the cost associated with the efforts, $I_{1}$ and $I_{2}$ increases. Also, the optimal sustainability communication effort $\left(\eta^{*}\right)$ increases as the social media interaction capability of the firm increases.

Proposition 2 Following relations hold true at the optima:

1. $\eta^{*}>\theta^{*}$, if $\left(\beta i I_{1}>\alpha I_{2}\right)$

2. If part (1) holds, then, $\beta i \eta^{*}>\alpha \theta^{*}$, if $(\beta i>\alpha)$

As noted earlier, consumers are more likely to fetch sustainability related information from social media than from the official reports (if any) published by the firms, i.e., $\beta i>\alpha$. Moreover, it is reasonable to assume that the cost of actual sustainability investment for a firm is going to be higher than the cost of communicating their initiatives through social media, i.e., $I_{1}>I_{2}$. Therefore, part 1 of proposition 2 always holds true, meaning that the optimal effort put in by the firm on social media communication is going to be higher than the actual sustainability investment effort, i.e., they talk more than they walk. Part 2 of proposition 2 states that the incremental demand due to the firm's social media communication effort on the overall consumer demand is significantly higher as against the incremental demand due to firm's actual sustainability investment.

It must be noted that for manufacturing firms (asset intensive) $I_{1} \gg I_{2}$, since sustainability investment for such firms involve modifying their core operations and processes which are expensive in nature. Hence, for manufacturing firms we expect $\eta^{*} \gg \theta^{*}$. Based on the results established thus far, we can see why some of the firms (particularly manufacturing firms) would go even further and communicate misleading sustainability information to their stakeholders in order to generate more firm value. This could very well be the reason behind some of the infamous sustainability scandals such as that of Volkswagen or more recently when H\&M was called out by the Norwegian consumer authority for vague sustainability claims around their manufacturing and sourcing practices (Segran, 2019).

We can visualize the result established in proposition 2 with Fig. 2 (Numerical data for Fig. 2 and 3 is provided in Table 7 in the Appendix). It shows how the difference between the optimal sustainability communication effort and the optimal sustainability investment effort increases as the cost of actual sustainability investment increases in comparison to the cost of communicating over social media. Moreover, we can see that as the interaction capability of the firm increases, so does the effort difference. Only for the cases where the interaction capability of a firm and the cost difference is very low, is where a firm puts in more effort in sustainability investment as compared to the effort in communicating the initiatives. 
Fig. 2 Impact of cost differential on the optimal effort differential at different values of interaction capability (i)

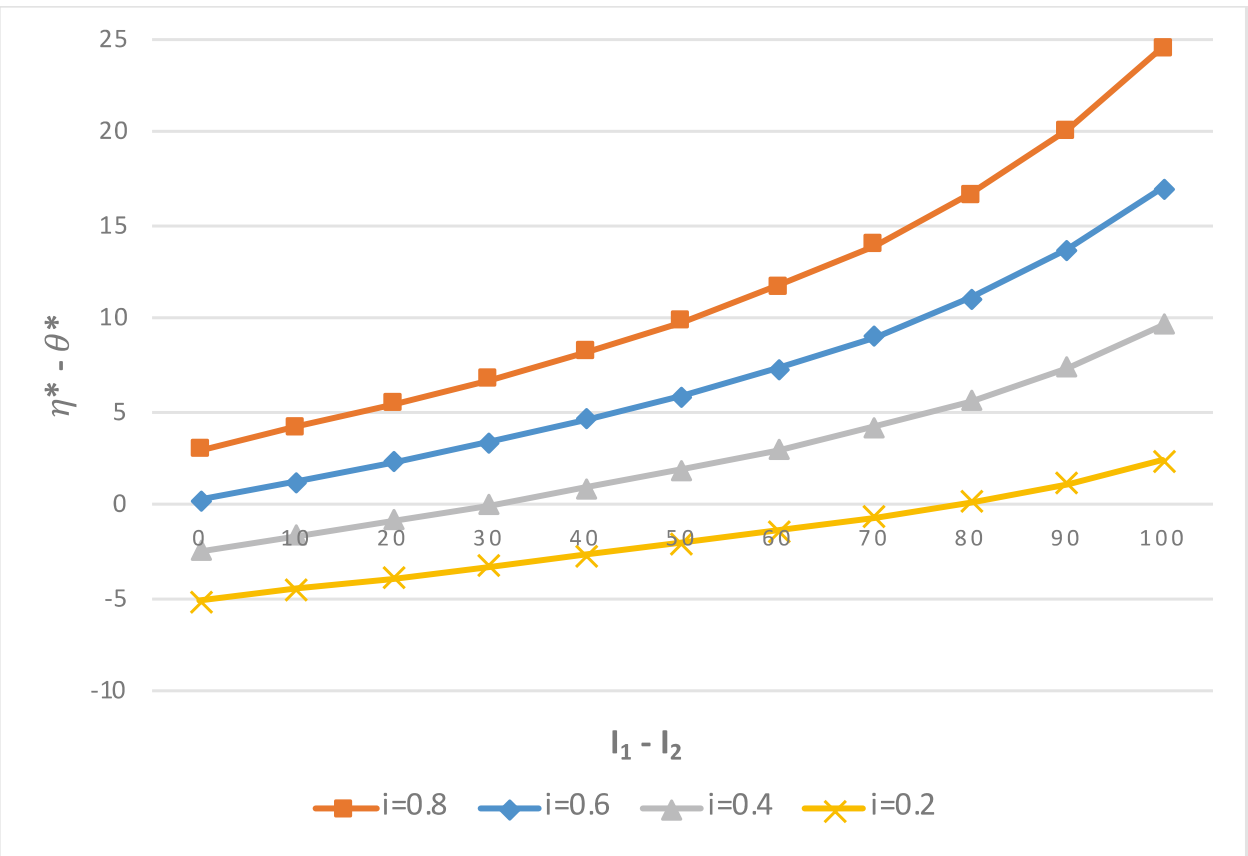

Proposition 3 Consider Firm 1 with larger market potential (size) than firm 2, i.e., $a_{1}>a_{2}$. We find that, ceteris paribus, $\frac{\beta i_{2} \eta_{2}^{*}}{a_{2}}>\frac{\beta i_{1} \eta_{1}^{*}}{a_{1}} \forall i_{2}^{2}>i_{1}^{2} \frac{a_{2}\left(a_{1}-b c\right)}{a_{1}\left(a_{2}-b c\right)}$

Here, $\frac{\beta i_{2} \eta_{2}^{*}}{a_{2}}$ and $\frac{\beta i_{1} \eta_{1}^{*}}{a_{1}}$ represents the relative contribution of the incremental demand due to each firm's social media communication effort. Proposition 3 implies that a smaller firm with strong social media interaction capability will generate more firm value as compared to a bigger firm with lower interaction capability. In fact, it is found that smaller firms do have better social media interaction capability than the larger firms (Braojos-Gomez et al., 2015). This is partly due to the reason that smaller firms are more community and individual focused. While larger firms have wider reach for their communication efforts owing to their higher spending and higher followers online, small firms with high degree of interaction owing to closer interaction (Foltean et al., 2019) would benefit more compared to large firms with lower interaction.

Figure 3 demonstrates the result established in proposition 3 . The horizontal axis represents the percentage market
Fig. 3 Firm market potential and interaction capability impact on the social media driven demand contribution

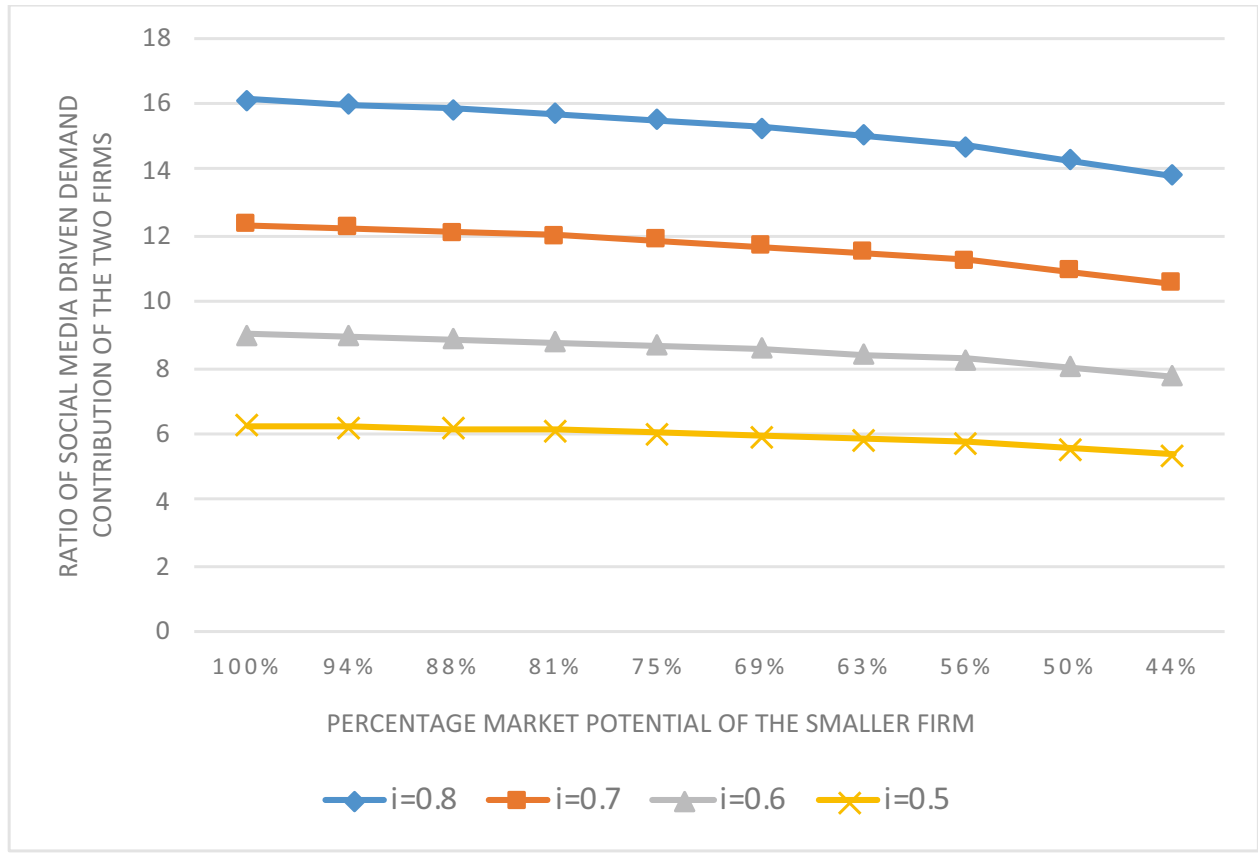


potential of the smaller firm, i.e., $\left[a_{s} / a_{b} * 100\right]$. The vertical axis represents the ratio of social media driven demand contribution for the two firms, i.e., $\left\{\frac{\beta i_{s} \eta_{s}}{a_{s}} / \frac{\beta i_{b} \eta_{b}}{a_{b}}\right\}$. We can see how a smaller firm with higher interaction capability (Bigger firm is assumed to have an interaction capability of 0.2 ) witnesses greater demand contribution from the social media communication efforts.

\section{Empirical Validation}

In this section, we present empirical validation of the analytical model that has been discussed in the previous section. While, analytical models have the benefit of establishing causality by analysis and also analyse and present solutions for complex business phenomenon, one of the criticisms of such models is complexity of interpretation in a world with no assumptions that hold in analytical models (Choi et al., 2016) as well as lack of evidence of direct application (Roth \& Rosenzweig, 2020). To quell such criticisms of our modelling approach, we have performed empirical validation of the core results of our analytical model. To achieve the same, we first present testable hypotheses. These hypotheses have been derived from the analytical model (having their base in sound analytical logic and backed by extant literature) discussed in preceding section. We then proceed to discuss relevant data and test the proposed hypotheses.

\subsection{Testable Hypotheses}

We formulate the testable hypotheses in this section to validate the assumption as well as the major results of our analytical model, thereby validating the overall theorization of our research problem. One of the first assumptions that we have made in the model is that sustainability communication on social media impacts the firm's demand. We measure demand in empirical terms as sales of the firm. Hence, the statement changes to that sustainability communication on social media significantly impacts a firm's sales. Proposition 1 in our model establishes the baseline assumptions and results for firm and consumer behaviour. Together the demand equation and proposition 1 leads us to the hypothesis that higher sustainability communication on social media $(\eta)$ would lead to higher sales of the firm as signified by significant $(\beta)$. Also proposition 2 establishes the basis for relationship between sustainability effort and communication effort. This leads us to the first two hypotheses:

H1: Higher sustainability communication of firm would be rewarded by consumers of a firm through higher sales.
H2: The relative effort put into social media communication (in contrast to sustainability investment effort) is going to be higher for the manufacturing firms than the services firms.

Together $\mathrm{H} 1$ and $\mathrm{H} 2$ empirically validates the theoretical proposition 2. Hypothesis 1 tests whether the consumer sensitivity $(\beta)$ towards the sustainability related social media communication of a firm is significant or not. Also, as established in Proposition 2, if the cost of sustainability investment is higher than the cost of communicating, i.e., $I_{1} \gg I_{2}$, the optimal effort put in by the firm on social media communication is going to be higher than the actual sustainability investment effort, i.e., $\eta^{*}>\theta^{*}$. We expect this effect to be much more pronounced for the manufacturing firms than the services firm, as the cost of actual sustainability investment for the manufacturing firms is usually very high $\left(I_{1} \gg I_{2}\right)$.

The baseline demand equation (Eq. 1) considers that the demand is dependent not just on firm's social media communication but also by firm's interaction with the consumers. In standalone terms too, this assumption has been validated in extant research that has found that firms that maintain continuous interaction with their consumers stand to gain more than others (Fuchs et al., 2010). In our case, this provides a basis for establishing the relation between sustainability communication and consumer demand as stated in hypothesis 3 .

H3: Consumer interaction would moderate the relationship between higher sustainability communication and its impact on sales.

H3 is the empirical test for theoretical model's formulation with regards to the social media interaction capability of a firm ( $i$ ). As formulated in the model, the interaction capability of a firm moderates the impact of the communication efforts made by the firm on its sales $(\beta i \eta)$.

Finally, we move to proposition 3 that establishes the impact of firm's size on the relationship between firm's communication efforts and its demand. The numerical analysis does establish that smaller firms will gain more, if they have higher interaction with consumers. The model's results also finds validation in extant research that has established that firm size is a significant predictor in the way consumer loyalty and interaction impacts firm's sales (demand) (Orth $\&$ Green, 2009). Since consumer loyalty and interaction in online space is viewed in similar terms to firm's offline loyalty, we can extend the arguments in offline marketing space that firm loyalty has a stronger impact on smaller firms. Hence, we hypothesize:

H4: Smaller firm with higher consumer interaction will have higher positive impact on sales due to increase in 
sustainability communication irrespective of firms sustainability investment efforts.

\subsection{Data and Method}

For this study, we have collected firm's social media activities data and firms' financial and sustainability performance data. For purpose of empirical analysis, we first need to establish the context of analysis before elaborating on data and method. As we mentioned in the introduction of the paper, the objective of this research is to study if sustainability sensitive stakeholders react to the sustainability specific communication of firms on social media. While, all firms can be stated to be sustainability sensitive to some extent. Neutral third party ratings, provide an independent metric that both firms and the consumers use to gauge those firms that are more sustainability centric than others (Hawn et al., 2018). Hence, in continuation with the practices in extant literature, we have analysed the hypotheses for these firms for whom signalling effect should be maximum. Establishing these results for firms with strong sustainability signals would establish the relationship between demand and firm's sustainability communications.

Hence, we have collected the data for all US listed firms in Dow Jones Sustainability Index (DJSI). DJSI is an index created jointly by S\&P Dow Jones Indices and RobecoSAM to create a benchmark for world's leading firms in terms of their performance in economic, environmental and social criteria (RobecoSAM, 2020). DJSI firms are the largest firms with known sustainability efforts and are closely tracked by investors with interests in social, environmental and sustainable practices (Hawn et al., 2018). As such these firms represent ones that are expected to have highest activity in the field of sustainability (for large publicly traded firms). Hence, the impact of social media activity for these firms vis-à-vis their sustainability efforts should ideally be lower compared to non DJSI listed firms. Hence, our results would be stronger for non DJSI firms.

For this study, we collected the list of DJSI firms listed in United states and then reduced our sample to those firms that had been using social media activity (Twitter) actively over a period of at least 4 years i.e. 2015-2018. For these firms we collected social media and financial data for period 2016-2018. To reduce the starting jump that a firm starting in 2015 may have had, we did not use data for 2015. Few firms discontinued their social media accounts in the study period and few got merged. We eliminated these firms and were finally left with 122 firms. Hence, our total dataset was a panel dataset with 122 entities over 3 time periods i.e. total of 366 firm year of data.

For these firms' social media data, we used twitter's API to collect data on their social media activities. We collected information of their tweets, retweets of their tweets, no. of followers, likes per post, no. of posts with images etc. To analyse their sustainability related social media activity, we created a vector of words and phrases related to sustainability. These words have been provided in the appendix. These vector of words were created through a thorough analysis of past literature in the field and were discussed with other researchers and experts. We used text analysis techniques to analyse all the tweets made by these firms in this 3-year period and identified the tweets that were sustainability specific. We have termed these as relevant tweets. Some examples of sustainability communication by firms are provided below

"Committing to sustainability at $3 M$ includes reducing our carbon footprint, integrating \#sustainability into all our new products and more.Read @ thomsonreuters' perspective on how $3 \mathrm{M}$ is committing to sustainability: https://blogs.thomsonreuters.com/ sustainability/2018/12/21/executive-perspectivea-100-year-old-company-leading-on-transparencyand-sustainability/"

"Yes, we're proud to share that all of our coffee is ethically sourced with a focus on sustainability. Read more here:https://sbux.co/2ATVUDi"

"Our \#sustainability strategy today engages nearly every aspect of our business. Take a look at how we're positively impacting \#appliances $\backslash x e 2 \backslash 80 \backslash \times 94$ and the \#homebuilding industry $\backslash x e 2 \backslash x 80 \backslash \times 94$ today. http://whrcorp.co/Dzkl7E"

Once we identified these tweets, we then created a set of metrics that were important for our analysis by using relevant text mining techniques (Kumar et al., 2021) as described below.

a. Proportion Relevant- Proportion relevant indicates the proportion of relevant i.e. sustainability specific posts that a firm is making using its social media channels. This metric is used to measure the construct of sustainability communication efforts of firm.

b. Average Retweets- The average number of retweets received by a firm's tweet. We then took the Log for linearization. The metric has been used to construct the measure of firm's interaction with its consumers. Extant research on social media trends has established that higher retweet rate is indeed a reflection of higher engagement between the tweeter (firm) and the retweeting parties (consumers) (Chahine \& Malhotra, 2018)

Other social media metrics that we created can be summarized as follows. These have been used as control variables to account for different kinds of activities that firms engage on in social media space. 
a. Tweets- The total number of tweets made by a firm per week. This accounts for the average activity of the firm on a weekly basis in social media. As there is huge disparity in social media activity of firms. We have used the natural $\log$ of the data for linearization.

b. Likes- The average number of likes received by a firm's tweets. We have used the natural log of the data for linearization.

c. Followers- The total number of followers a firm's twitter account has. We have used the natural log of the data for linearization.

d. Images- Average number of tweets with images that a firm shares. It has been used as a control as past literature has shown that posts with images receive higher user interaction than non-image based posts.

For firm's financial and sustainability performance data, we downloaded the data from Bloomberg and this included data for their financial/accounting performances as well as their sustainability metrics.

a. Sales- Annual sales data for 2016-2018 was downloaded and used. Sales was used as a metric of indicating consumers demand. We used natural logarithms.

b. SIC- We used standard industry classification (SIC) codes to divide firms into asset heavy manufacturing, mining and construction firms for whom sustainability is relatively investment heavy versus services firm for whom investment in sustainability is expected to be lower.

c. Employees- We used number of employees of a firm as a proxy for size of firm. We used natural log of the values.
It was used as a control and for moderation test in some hypotheses.

d. Market Capital- We used natural logarithm of a firm's market capitalization at the end of the calendar year when their sales figure were announced for 2016-2018 to account for their investor's relationship to the firm.

e. ESG Score- A firm's investment in sustainability is hard to ascertain and various studies have used different metrics as a measure of firm's sustainability efforts. We have used their ESG scores as a metric of a firm's real sustainability efforts. These scores are provided by Bloomberg® for all participating firms after analysing their efforts towards environment and social sustainability. An important point to note is that ESG scores are industry normalized.

Table 2 provides the descriptive statistics and correlation matrix for the study variables.

\section{Results}

The first set of analysis attempts to understand the response of consumers through the consumption of the firms' products as a response to their sustainability efforts. In this set of analysis we set our dependent variable to be the sales (natural logarithm). Table 3 shows the results of the analysis where we had just the core explanatory variables in model 1 . In model 2 we included the firm classification where manufacturing is a dummy variable that is set to 1 for asset heavy industries like manufacturing, construction, mining etc. and 0 otherwise. In model 3 we add additional moderation

Table 2 Descriptive statistics and Pearson correlation matrix

\begin{tabular}{|c|c|c|c|c|c|c|c|c|c|}
\hline & Mean & S.D & 1 & 2 & 3 & 4 & 5 & 6 & 7 \\
\hline Manufacturing & 0.602 & 0.490 & 1 & & & & & & \\
\hline EMPLOYEES & 69075.697 & 89481.319 & $-0.106^{*}$ & 1 & & & & & \\
\hline SALES & 29644.771 & 37326.299 & -0.065 & $0.626 * *$ & 1 & & & & \\
\hline MARKET_CAP & 60949.693 & 80077.512 & -0.026 & $0.348 * *$ & $0.560 * *$ & 1 & & & \\
\hline ESG SCORE & 48.603 & 9.434 & $0.319 * *$ & 0.081 & $0.108 *$ & $0.162 * *$ & 1 & & \\
\hline followers count & 431789.300 & 1508327.485 & -0.078 & $0.230 * *$ & $0.158 * *$ & $0.416^{* *}$ & 0.066 & 1 & \\
\hline Tweets & 371.818 & 2223.139 & 0.064 & 0.046 & 0.031 & -0.032 & 0.004 & $0.145 * *$ & 1 \\
\hline Likes & 27.358 & 84.031 & -0.048 & $0.203 * *$ & $0.203 * *$ & $0.390 * *$ & 0.055 & $0.369 * *$ & -0.035 \\
\hline Retweets & 10.641 & 30.533 & -0.034 & $0.198 * *$ & $0.195 * *$ & $0.407 * *$ & 0.057 & $0.390 * *$ & -0.04 \\
\hline Images & 41.670 & 29.201 & 0.068 & 0.002 & -0.08 & 0.017 & 0.026 & $-0.146 * *$ & $-0.185 * *$ \\
\hline \multirow[t]{2}{*}{ Proportion relevant (\%) } & 1.839 & 3.286 & $0.176 * *$ & -0.039 & $0.143 * *$ & $-0.160 * *$ & $0.114^{*}$ & $-0.126^{*}$ & -0.076 \\
\hline & & & 8 & 9 & 10 & & & & \\
\hline Likes & & & 1 & & & & & & \\
\hline Retweets & & & $0.841 * *$ & 1 & & & & & \\
\hline Images & & & $0.146 * *$ & $0.127 *$ & 1 & & & & \\
\hline Proportion relevant & & & 0.079 & 0.036 & $0.161 * *$ & & & & \\
\hline
\end{tabular}

*Correlation is significant at the 0.05 level (2-tailed). $* *$ Correlation is significant at the 0.01 level (2-tailed) 


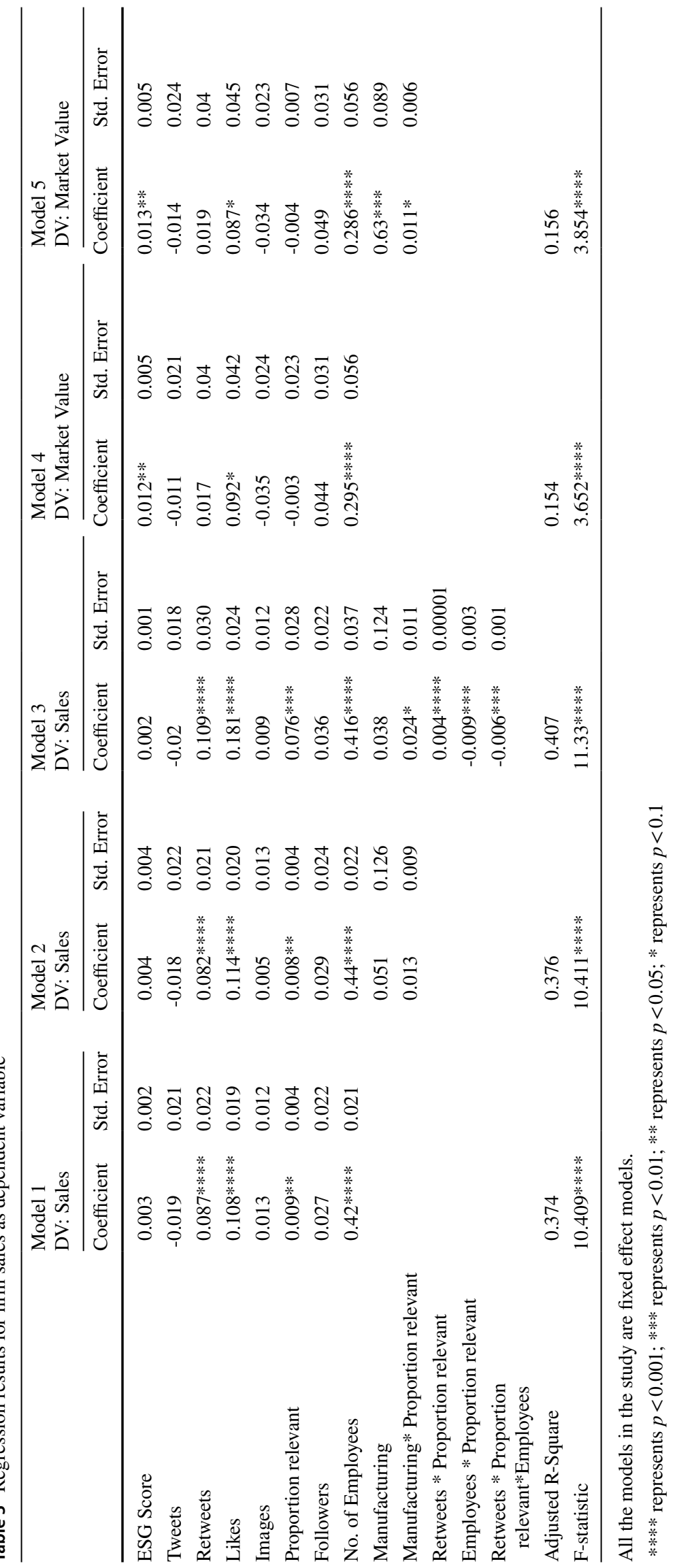


variables to test our hypotheses. All the models are fixed effect models with industry fixed effects. The panel was balanced with 366 firm-year data points.

The results indicate that ESG score, that represents a firm's sustainability efforts, have no impact on consumer demand i.e. ESG score does not impact a firm's sales. However, we find that sustainability communication on social media as operationalized through relevant tweets has positive and significant effect on the firm's sales. Hence, we find support for our Hypothesis H1.

Our second hypothesis concerned the impact of firms' capital intensive nature i.e. manufacturing or not being an indicator on the amount of effort put in social media communication. We have represented the results in Table 4 where we have reported the mean values of ESG and proportion relevant tweets as well as the mean values of these variables normalized by the maximum value in the respective set. The results in Table 4 indicate that while manufacturing and non-manufacturing firms have put almost equal efforts in sustainability (as reflected by ESG scores), manufacturing firms have communicated disproportionately more than non-manufacturing firms. This supports our hypothesis 2 .

Model 3 is also used to dive deeper into the effect of other moderating variables in the analysis. The results in Table 3 indicates that high retweet rate (An indicator of higher interaction) moderates the relationship between sustainability communication and consumer demand giving support for our hypothesis $\mathrm{H} 3$. We also find that size of a firm, represented through the number of employees, has a significant and negative moderation effect on its sustainability communication. We perform a 3-way moderation test with interaction and firm size, both as moderators (da Silva Faia \& Vieira, 2018). The negative coefficient indicates that a smaller firm with higher interaction shall have higher benefits of sustainability communication. Hence our hypothesis H4 was also supported.

\subsection{Robustness Test}

We check the robustness of our results to the choice of our dataset. A criticism may be levied over our choice of the DJSI listed firms for data analysis. We tested the complete

Table 4 ANOVA and Descriptive comparison

\begin{tabular}{lllll}
\hline & $\begin{array}{l}\text { ESG } \\
\text { normalized } \\
\text { Mean }\end{array}$ & $\begin{array}{l}\text { Prop relevant } \\
\text { normalized } \\
\text { Mean }\end{array}$ & ESG mean & $\begin{array}{l}\text { Prop } \\
\text { relevant } \\
\text { mean }\end{array}$ \\
\hline $\begin{array}{c}\text { Non-Manufac- } \\
\text { turing }\end{array}$ & 0.583 & 0.055 & 0.922 & 0.622 \\
$\begin{array}{c}\text { Manufacturing } \\
\text { ANOVA } \\
\text { p-value }\end{array}$ & 0.664 & 0.110 & 1.050 & 1.245 \\
\hline
\end{tabular}

Table 5 Supplementary analysis non-DJSI and DJSI listed firms' comparison

\begin{tabular}{llllll}
\hline Group & & Sales & Market Cap & ESG & $\begin{array}{l}\text { Propor- } \\
\text { tion } \\
\text { Relevant }\end{array}$ \\
\hline Non-DJSI & 40 & 66952.49 & 136237.97 & 40.879 & 1.154 \\
DJSI & 122 & 29788.05 & 61111.18 & 48.616 & 1.854 \\
ANOVA & & $70.76^{* * * *}$ & $111.6^{* * * *}$ & $52.56^{* * * *}$ & $3.17^{*}$ \\
\hline
\end{tabular}

$* * * *$ represents $p<0.001$; *** represents $p<0.01$; ** represents $p<0.05 ; *$ represents $p<0.1$

model specifications i.e. model 3 (as well as supplementary model 5) for non-DJSI listed firms. The results are contained in model 6 (for sales as dependent variable) and model 7 (for market value as dependent variable) in Table 6 . To compare these firms, we have used ANOVA to compare the stats for these two groups of firms ${ }^{1}$ with results represented in Table 5. This shows that while DJSI listed firms, as expected, have higher ESG score (40.879 vs. 40.616 for non-DJSI firms), they also invest a lot more in sustainability communication as evident by higher proportion of relevant tweets (1.854\% vs $1.154 \%$ for non-DJSI firms). We also find that non-DJSI listed firms have higher sales and market capitalization. This may be because these firms have bigger market and more wider investor network. Our analysis in model 6 and 7 indicate that ESG score continues to have an impact on both sales and market value of firms.

\subsection{Instrumental Variable Analysis}

Second and most critical of the robustness analysis is for endogeneity. In the preceding analysis multiple steps were taken to ensure that endogeneity issue is minimized by use of theoretically sound variables, analysing relationships that were theoretically established and use of host of control variables to limit issues like reverse causality, simultaneity and omitted variables. However, the issue of endogenous effects is difficult to predict and remove. Extant literature has suggested use of instrumental variable approach as the preferred method of analysing variables with possible endogenous behaviour (Ferreira et al., 2019). In our case, we have two possible sources of endogeneity. The first being ESG score and the second one being social media engagement with users like retweets. It can be argued that firm with higher resources have higher capacity to undertake these initiatives and have higher engagement. Therefore, even with all

\footnotetext{
${ }^{1}$ For the supplementary analysis of non-DJSI listed firms, we curated the data for those S\&P 500 firms that were not listed in DJSI, were listed in US Stock exchange and had an active social media presence for past 4 years and were traded for full 4 years i.e. were not bankrupted or bought over.
} 


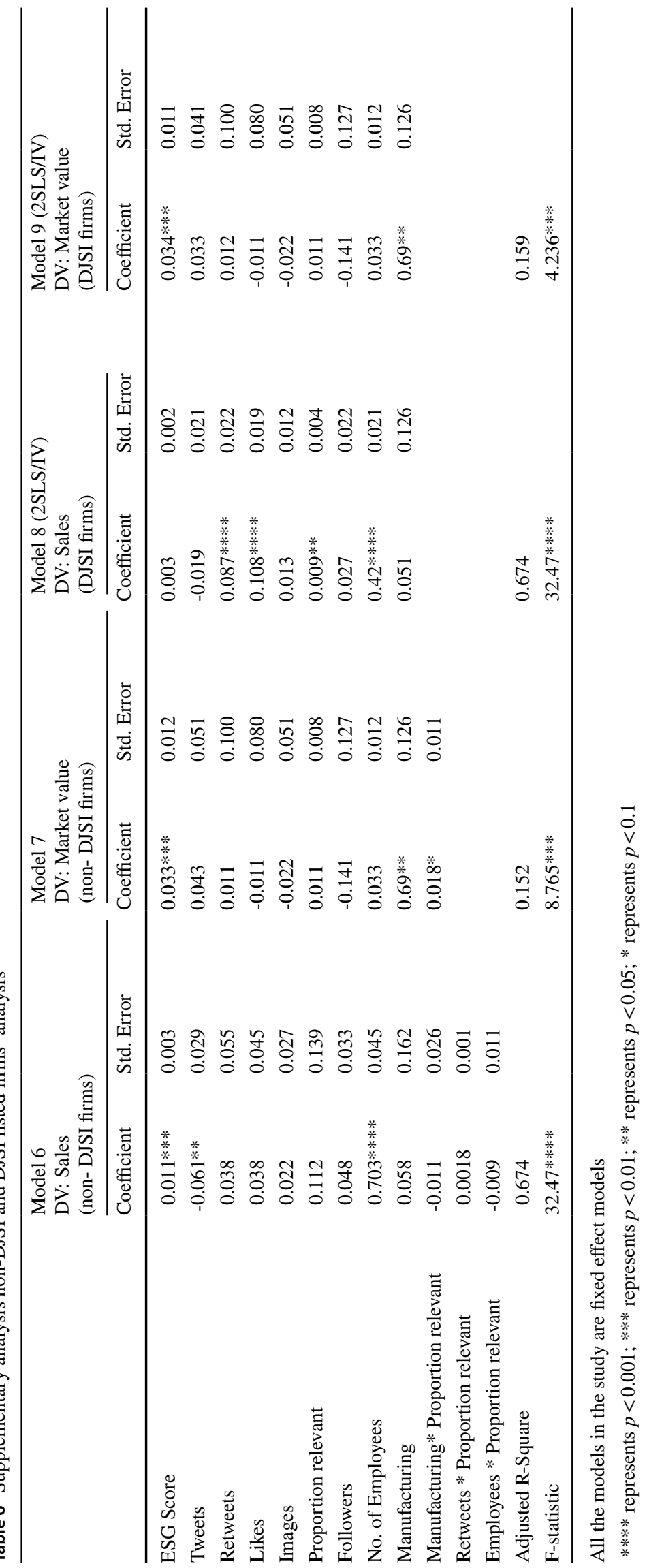


controls in place, there remains a possibility of endogenous effect of firm resources/size on these explanatory variables. Hence, we have used instrumental variable (IV) analysis to mitigate this issue. In any IV analysis, the biggest challenge is in establishing the correct IV itself. In absence of past studies in this domain, it was indeed challenging to find the right variables to be treated as IV.

We have identified two instrumental variables. We have instrumented ESG score with percentage of women directors on board of firms. Previous studies have indicated that firms with higher representation of women in their boards have higher standards of corporate governance (Naciti, 2019). These firms also have higher commitment to sustainability expectations of the shareholders of the firms (Ben-Amar et al., 2017). On the other hand, relationship between women's board representation and firm's consumer sales are scant and non-established. While it is possible that firms with higher women representation have higher sales, the effect would be indirect through enhanced firm governance and sustainability strategy and not directly. Hence, we believe that it is an appropriate IV for ESG score.

The second IV that we have used is the age of twitter account to instrument the retweets of a firm's social media posts. While it may be argued that firms with higher resources may invest in social media activities to generate higher retweets, twitter age (computed as time elapsed since a firm's twitter account was established) can be considered independent of firm resources. This is because twitter accounts have been free for corporate use as well ${ }^{2}$ (O'Reilly $\&$ Milstein, 2011). Higher twitter age represents greater social media awareness of a firm and its strategic tilt towards use of social media as a mode of communication (O'Reilly \& Milstein, 2011). Older social media profiles have higher interaction with their followers and hence have higher retweet rate (Metaxas et al., 2015). While older twitter accounts may be correlated with higher firm sales, this is not caused by firm's twitter account age and any impact on firm sales is due to the twitter age variable impacting retweet counts.

We use two-stage least squared (2SLS) method to estimate the IV regression for both the variables. The analysis has been performed for our primary dataset of DJSI listed firms. Detailed results have been provided in Table 6 in models 8 and 9 with the dependent variables of sales and market value respectively. The results indicate that none of the two instrument variables are weak as we were able to reject the weak IV hypothesis. Also, the Wu-Hausman test statistic represents presence of endogeneity in both the models with sales (coef $=5.571, p<0.001)$ as well as market capitalization as dependent variables (coef $=6.08, p<0.001)$. We

\footnotetext{
$\overline{2}$ While firms may use sponsored posts to have higher reach, basic use of twitter is free for corporates as well.
}

find that the overall effects of our explanatory variables i.e. retweets and ESG score is lower than estimated using non IV endogenous model. However, the results are qualitatively same, indicating our hypothesis to be robustly validated.

\section{Discussion and Implications}

One of the key objectives of our study was to investigate the impact of firm generated sustainability-related social media communication on its market value. In this respect, owing to the support we find for $\mathrm{H} 1$, we can conclude that consumers indeed are green-sensitive and are tangibly receptive towards a firm's sustainability-related social media communication, leading to a significant positive impact on firm value. It is also relevant to note that a firm's ESG rating has no impact on consumer purchase decisions. The finding emphasizes the role of social media as the mode of firm communication directed towards its customers, confirming the need for easily comprehensible and digestible information (Fischer et al., 2016). Moreover, consumers appreciate firms' sustainability efforts, but they do not intend to track and verify firms' actual actions.

The second key objective of our study was to investigate the conditions under which firms disproportionately communicate their sustainability efforts on social media. We find support for $\mathrm{H} 2$, i.e., the more a firm belongs to an industry/ environment where actual sustainability investment is costly, the more disproportionately it communicates its efforts on social media.

We have also used model 2 to dive deeper into this result. While the ANOVA analysis from Table 4 shows that manufacturing and non-manufacturing firms behave differently. It needs to be seen how consumers react to these firms and do consumers distinguish between these firms or not. Results from Model 2 as depicted in Table 3 shows that consumers do not distinguish between manufacturing and non-manufacturing firms. This should be expected as most consumers are not savvy enough to understand the difference in nuances between manufacturing and non-manufacturing firms' sustainability requirements and trust firms' communication as an indicator of sustainability and award those firms that show high sustainability through its communication. Model 2 and Model 3's results for moderation between manufacturing firms and relevant tweets does provide limited evidence that consumer demand rises for those manufacturing firms that communicate more.

\subsection{Supplementary Analysis}

To dive deeper into the results from our analysis, we conduct a supplementary analysis that relates to the impact of 
'type of firm stakeholder'. The analysis and the models so far have been with the perspective of consumers. Along with consumers, another important segment of stakeholders is of investors or shareholders. As more nuanced participants in firms' operations, this group is exposed to the ratings and rankings on sustainability provided by the rating agencies (Hawn et al., 2018). They use the information from these agencies as a signal to gauge the sustainability practices of a firm.

Theory suggests that firms with higher investment in sustainability, as reflected through higher ESG score will be rewarded by its investors through higher market value (Hawn et al., 2018; Robinson et al., 2011). As manufacturing firms face numerous difficulties in implementing sustainability practices owing to cost and operational challenges, manufacturing firms with higher ESG scores will see higher market value than non-manufacturing firms. The results for the previous assertion failed for consumers where manufacturing firms' demands was not significantly different from non-manufacturing firms' demands. However, our assertion is that higher effort required by manufacturing firms will be appreciated and rewarded by investors of firms. Models 4 and 5 in Table 3 show the results of our analysis for investor response as impacted by sustainability efforts and communication. Model 4 shows that ESG score has a positive and significant effect on a firm's market value $(p<0.01$, coef $=0.012)$. We also find that a firm's sustainability communication on social media does not impact a firm's market valuation. Through model 5, we also find evidence for differentiated impact of manufacturing firms' sustainability efforts on its valuation (coef $=0.63, p<0.01$ ). We find that the dummy variable manufacturing positively moderates the relation between ESG score and the firm valuation ( coef $=0.011, p<0.05)$. This leads us to the conclusion that investors value a manufacturing firm's sustainability efforts higher than a nonmanufacturing firm's sustainability efforts. Extant literature has not found clear evidence of increase in firm value through inclusion in metrics like DJSI etc. (Hawn et al., 2018; Kim \& Lyon, 2015). Our study indicates that while it may be possible, firms already in DJSI will be positively rewarded by investors for enhanced sustainability activities.

\subsection{Implications for Practice}

Our study has implications for the policy makers, the firms, and the stakeholders.

\section{Recommendations for policy makers:}

a) The study establishes both theoretically and empirically that the firms at the end of the day being profit maximizers have every incentive to be disproportionate with regards to their sustainability 'walking' and 'talking'.
It is therefore imperative for the policymakers to come up with suitable measures to keep watch and ensure the transmissions of correct and proportionate information on the sustainability initiatives to the stakeholders of a firm. As has been established in our research, asset heavy firms need more scrutiny as they carry an increased risk of disproportionate/misleading information. Policymakers/enforcers should keep in mind that the consumers would keep on accessing the information through social media given its user friendly structure, and therefore policy institutions' own presence and information disbursement will go a long way.

b) One way to do it is to identify the most likely misleading information for each industry based on past trends. For instance, California state law bans any plastic product that is labelled as "biodegradable" or "compostable" unless it has complete information about how quickly the product will biodegrade (Corcione, 2020). In a similar manner, policy institutions can identify the typical misleading information in various industries and impose a restriction even over social media.

\section{Recommendations for firms:}

a) Through this research, for the first time, it is clearly established that social media is the preferred channel of information for the consumers, whereas, on the other hand, investors prefer more formal channels to access information on a firm's sustainability initiatives. Therefore, to say the least, firms should consider different communication strategies as far as different stakeholders are concerned.

b) The research also explores the role of the social media 'interaction capability' of a firm. We find that the firms that have higher interaction with their consumers over social media generate higher sales through sustainability conscious consumers. Firms, therefore, should not only have a strong communication presence over social media but should also keep it interactive throughout.

c) We find (theoretically and empirically) that more the cost difference between actual sustainability investment and the sustainability communication, firms have a tendency of 'talking' more than they really 'walked'. Given the 'greenwashing' reporting is increasing day by day, indulging in such activities will lead to higher consumer disutility and thereby lower profits for the firms. Hence, firms should be careful in indulging in such practices.

\section{Recommendations for investors and consumers:}

a) The stakeholders too have some key takeaways from this research. It involves more in being a green consumer 
than just fetching the information. As is clear from our research, firms have every incentive to mislead their consumers and hence a green consumer should also be able to parse out the relevant information from the heap of communication made by a firm.

b) Although investors being more sophisticated information seekers are at a lower risk of getting misled, it does not harm them to be extra careful given the high stakes involved.

\subsection{Theoretical Implications}

Our study contributes to the existing literature on multiple fronts. The implications of this study are particularly relevant to the information systems and sustainability literature. Our study is the first to theoretically model and empirically test the interplay between sustainability and social media. This study is also the first to establish that green consumers are, infact, fetching sustainability information through social media and making their purchase decisions accordingly. As such, we extend the literature in domain of impact of social media for socially relevant issues like CSR, social marketing etc.(Chae \& Park, 2018; Huang et al., 2019).

Moreover, the adoption of a mixed-method research design makes our paper relevant for both the empirical and analytical literature streams. This adds to the growing mixedmethod research in the field of information systems with an aim to increase research validity and robustness (Kar, 2020). A growing dimension in information systems research has been to utilize data analytic based methods in socially relevant research (Ghosh \& Sanyal, 2021; Kapoor et al., 2021). This study, with its focus on sustainability related communication adds to this growing field of research.

We provide a mechanism to model and theoretically test propositions in the domain of social media communication. This brings two disparate groups of study together. The demand model treatment in our paper is novel with respect to existing models in the sustainability literature. The model presented in our paper is the first where the inherent assumption of green consumers making decisions based on actual sustainability investment is relaxed. The demand structure as modelled in our paper can be used for analysing many other management contexts where there is a distinction between 'effort' and 'communication of effort'. As established in the analytical model, we find evidence for firm behaviour that asset heavy firms (particularly manufacturing firms) due to the high cost of sustainability investment tend to communicate much more than their actual sustainability efforts.

\section{Conclusion}

Like all pieces of research, this paper is not without its share of limitations that provide opportunities to enhance and extend the work in future. We have established the impact of communication on social media on a firm's consumer demand. However, we have not compared the differential impact on sustainability sensitive consumers who are inactive on social media. An experimental study that compares active and inactive consumers on social media would be better able to provide the marginal effect of social media communication for firms. We have also limited ourselves to the generic definition of sustainability that includes all kinds of sustainability specific activities. The authors admit the presence of vast diversity in terms of sustainability activities and the fact that some consumers may be more sensitive to some of these activities over others that needs to be studied further in subsequent studies. As a first paper attempting to establish the relationship between sustainability initiatives, social media communication and consumer demand, we have relied on DJSI-listed firms to study those firms that have pre-existing market signals for being sustainability sensitive. A wider study encompassing different kinds of firms with different sustainability statuses in different geographies may provide more generalizable results. Additionally, ESG scores that we have used to construct the measure for sustainability effort, though acceptable, may not be without its limitations. A more specific metric of sustainability effort by firms would be better able to study the theoretical propositions that we have established.

Even with its limitations, this paper contributes to the extant literature in ways more than one. The key contributions of our study are that a.) this is the first paper to find the evidence of social media driven purchase decisions by the sustainability conscious consumers, $b$ ) it is also the first paper to analytically model a firm's decision making while simultaneously considering firm's sustainability effort and the corresponding communication effort, and c) we find the empirical evidence of firms' sustainability behaviour as established in the theoretical model.

\section{Appendix}

List of keywords used for selecting the relevant tweets for sustainability by firms 


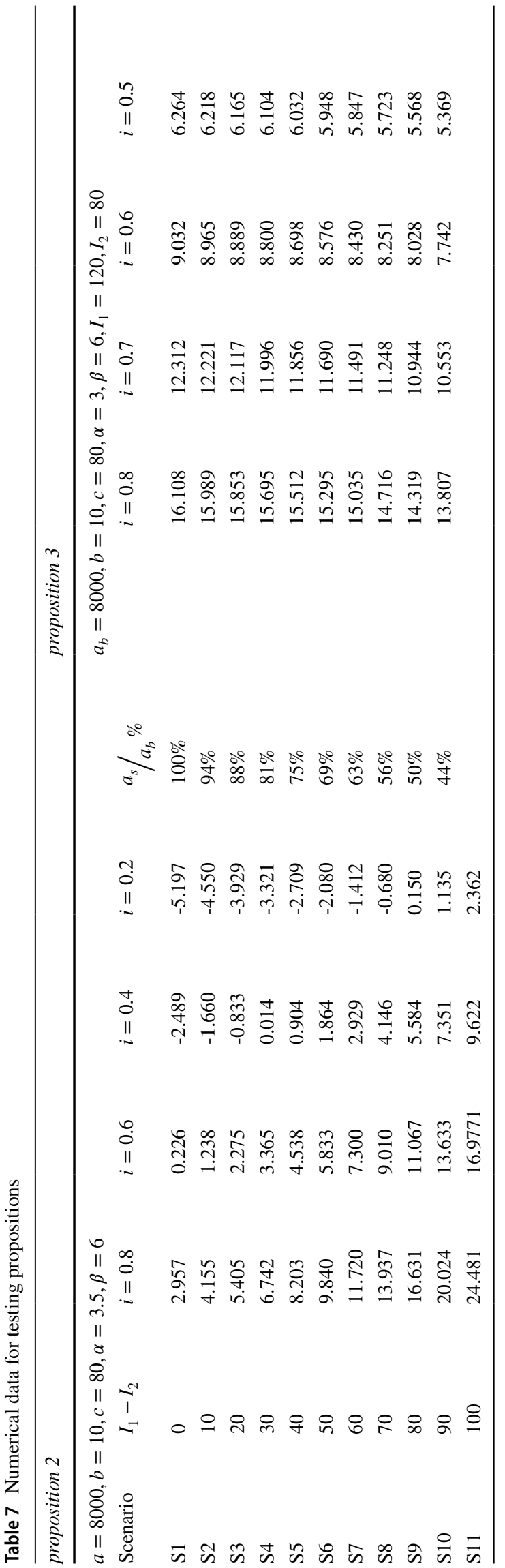

\begin{tabular}{|c|c|c|c|}
\hline $\begin{array}{l}\text { - Sustainability } \\
\text { - Green Supply } \\
\text { Chain } \\
\text { - Sustainable } \\
\text { Supply Chain } \\
\text { - Sustainable } \\
\text { Operations } \\
\text { - Climate } \\
\text { Change } \\
\text { - Plastic Free } \\
\text { - Sustainable } \\
\text { Practice } \\
\text { - Environment } \\
\text { Protection } \\
\text { - Environment } \\
\text { Conservation }\end{array}$ & $\begin{array}{l}\text { - Earth Day } \\
\text { - Carbon Tax } \\
\text { - Air Pollution } \\
\text { - Ecological } \\
\text { Diversity } \\
\text { - Sustainable } \\
\text { Design } \\
\text { - Biodiversity } \\
\text { - Biodiversity } \\
\text { Conservation } \\
\text { - Emission } \\
\text { control } \\
\text { - Water man- } \\
\text { agement } \\
\text { - Sustainable } \\
\text { Engineering }\end{array}$ & $\begin{array}{l}\text { - Endangered } \\
\text { Species } \\
\text { - Energy Con- } \\
\text { servation } \\
\text { - Global } \\
\text { Warming } \\
\text { - Green Prod- } \\
\text { ucts } \\
\text { - Green Tech- } \\
\text { nology } \\
\text { - Greenhouse } \\
\text { Effect } \\
\text { - Oil Spills } \\
\text { - Land Pollu- } \\
\text { tion } \\
\text { - Water Pollu- } \\
\text { tion } \\
\text { - Recycling } \\
\text { - Renewable } \\
\text { Energy } \\
\text { - Solar Energy }\end{array}$ & $\begin{array}{l}\text { - Natural } \\
\text { resource con- } \\
\text { servation } \\
\text { - Wastewater } \\
\text { treatment } \\
\text { - Waste manage- } \\
\text { ment } \\
\text { - Environmental } \\
\text { sustainability } \\
\text { - Carbon emis- } \\
\text { sions } \\
\text { - Workplace } \\
\text { safety } \\
\text { - Human sus- } \\
\text { tainability } \\
\text { - Water Conser- } \\
\text { vation } \\
\text { - Social sustain- } \\
\text { ability }\end{array}$ \\
\hline
\end{tabular}

$\partial p^{2} \quad \partial p \partial \theta \quad \partial p \partial \eta \quad-2 b \quad \alpha \quad \beta i$

ProofofProposition 1 Hessian: $\partial \theta \partial p \quad \partial \theta^{2} \partial \theta \partial \eta=\begin{array}{lll}\alpha & -2 I_{1} & 0\end{array}$ $\partial \eta \partial p \partial \eta \partial \theta \quad \partial \eta^{2} \quad \beta i \quad 0 \quad-2 I_{2}$

The objective function is strictly concave if the Hessian matrix is negative definite. We find the hessian to be negative definite if $4 b I_{1} I_{2}>\left(\alpha^{2} I_{2}+\beta^{2} i^{2} I_{1}\right)$. Since, the cost parameters $\left(I_{1} \& I_{2}\right)$ are sufficiently high and price sensitivity of demand is high as compared to that of sustainability sensitivity of demand, the concavity condition will always hold true. By setting the first order derivatives to zero and solving for $p^{*}, \theta^{*}$, and $\eta^{*}$, gives us the following:

$$
\begin{gathered}
p^{*}=\frac{2 I_{1} I_{2}(a+b c)-c\left(\alpha^{2} I_{2}+\beta^{2} i^{2} I_{1}\right)}{4 b I_{1} I_{2}-\left(\alpha^{2} I_{2}+\beta^{2} i^{2} I_{1}\right)}, \\
\theta^{*}=\frac{\alpha I_{2}(a-b c)}{4 b I_{1} I_{2}-\left(\alpha^{2} I_{2}+\beta^{2} i^{2} I_{1}\right)} \\
\eta^{*}=\frac{\beta i I_{1}(a-b c)}{4 b I_{1} I_{2}-\left(\alpha^{2} I_{2}+\beta^{2} i^{2} I_{1}\right)}
\end{gathered}
$$

\section{Proof of Lemma 1}

1. $\frac{\partial \theta^{*}}{\partial I_{1}}=\frac{\left.-\left[4 b I_{2}-\beta^{2} i^{2}\right)\right]\left[I_{2} \alpha(a-b c)\right]}{\left[4 b I_{1} I_{2}-\left(\alpha^{2} I_{2}+\beta^{2} i^{2} I_{1}\right)\right]^{2}}<0$, since 1.) $a>b c$ for a feasible price, i.e., $\quad p^{*}>c, \quad$ and 2.) $4 b I_{2}-\beta^{2} i^{2}>0$, since $4 b I_{1} I_{2}-\left(\alpha^{2} I_{2}+\beta^{2} i^{2} I_{1}\right)>0($ established earlier).

2. $\frac{\partial \eta^{*}}{\partial I_{2}}=\frac{\left.-\left[4 b I_{1}-\alpha^{2}\right)\right]\left[I_{1} \beta i(a-b c)\right]}{\left[4 b I_{1} I_{2}-\left(\alpha^{2} I_{2}+\beta^{2} i^{2} I_{1}\right)\right]^{2}}<0$, since 1.) $a>b c$ for a feasible price, i.e., $p^{*}>c$, and 2.) $4 b I_{1}-\alpha^{2}>0$, since $4 b I_{1} I_{2}-\left(\alpha^{2} I_{2}+\beta^{2} i^{2} I_{1}\right)>0($ established earlier).

3. $\frac{\partial \eta^{*}}{\partial i}=\frac{\left[I_{1} \beta(a-b c)\right]\left[4 b I_{1} I_{2}-\alpha^{2} I_{2}+\beta^{2} i^{2} I_{1}\right]}{4 b I_{1} I_{2}-\left(\alpha^{2} I_{2}+\beta^{2} i^{2} I_{1}\right)^{2}}>0$, since 1.) $a>b c$ for a feasible price, i.e., $p^{*}>c$, and 2.) 
$4 b I_{1} I_{2}-\alpha^{2} I_{2}+\beta^{2} i^{2} I_{1}>0$, since $\quad 4 b I_{1} I_{2}-\left(\alpha^{2} I_{2}+\beta^{2} i^{2} I_{1}\right)>0$

(established earlier).

\section{Proof of Proposition 2}

1. $\eta^{*}>\theta^{*}$ implies, $\frac{\beta i I_{1}(a-b c)}{4 b I_{1} I_{2}-\left(\alpha^{2} I_{2}+\beta^{2} i^{2} I_{1}\right)}>\frac{\alpha I_{2}(a-b c)}{4 b I_{1} I_{2}-\left(\alpha^{2} I_{2}+\beta^{2} i^{2} I_{1}\right)}$ implies, $\beta i I_{1}>\alpha I_{2}$

2. Given part 1 of proposition is true, we can conclude that $\beta i \eta^{*}>\alpha \theta^{*}$, if $(\beta i>\alpha)$.

Proof of Proposition 3 Assuming firm 1 as the bigger firm and firm 2 as the smaller firm, i.e., $a_{1}>a_{2}$. We have,

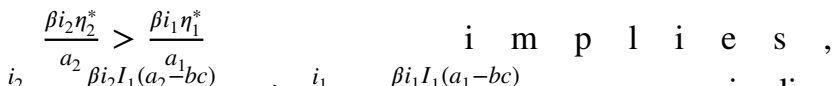

$$
\begin{aligned}
& \frac{i_{2}}{a_{2}} \cdot \frac{a_{2} \beta i_{2} I_{1}\left(a_{2}-b c\right)}{4 b I_{1} I_{2}-\left(\alpha^{2} I_{2}+\beta^{2} i_{2}^{2} I_{1}\right)}>\frac{i_{1}}{a_{1}} \cdot \frac{\beta i_{1} I_{1}\left(a_{1}-b c\right)}{4 b I_{1} I_{2}-\left(\alpha^{2} I_{2}+\beta^{2} i_{1}^{2} I_{1}\right)} \quad \text { implies, } \\
& i_{2}^{2}\left(a_{2}-b c\right) a_{1}\left(4 b I_{1} I_{2}-\left(\alpha^{2} I_{2}+\beta^{2} i_{1}^{2} I_{1}\right)\right)>i_{1}^{2}\left(a_{1}-b c\right) \\
& a_{2}\left(4 b I_{1} I_{2}-\left(\alpha^{2} I_{2}+\beta^{2} i_{2}^{2} I_{1}\right)\right)
\end{aligned}
$$

Also, it is noted that $\frac{a_{2}\left(a_{1}-b c\right)}{a_{1}\left(a_{2}-b c\right)}>1$, since $a_{1}>a_{2}$ and $\left(a_{1}, a_{2}\right)>b c$. Therefore, $i_{2}^{2}>i_{1}^{2} \frac{a_{2}\left(a_{1}-b c\right)}{a_{1}\left(a_{2}-b c\right)}$ implies $i_{2}>i_{1}$, implies $\left(4 b I_{1} I_{2}-\left(\alpha^{2} I_{2}+\beta^{2} i_{1}^{2} I_{1}\right)\right)>\left(4 b I_{1} I_{2}-\left(\alpha^{2} I_{2}+\beta^{2} i_{2}^{2} I_{1}\right)\right)$ and hence $\frac{\beta i_{2} \eta_{2}^{*}}{a_{2}}>\frac{\beta i_{1} \eta_{1}^{*}}{a_{1}}$.

Funding Open Access funding provided by the IReL Consortium.

Declarations All authors certify that they have no affiliations with or involvement in any organization or entity with any financial interest or non-financial interest in the subject matter or materials discussed in this manuscript. The authors did not receive support from any organization for the submitted work.

Open Access This article is licensed under a Creative Commons Attribution 4.0 International License, which permits use, sharing, adaptation, distribution and reproduction in any medium or format, as long as you give appropriate credit to the original author(s) and the source, provide a link to the Creative Commons licence, and indicate if changes were made. The images or other third party material in this article are included in the article's Creative Commons licence, unless indicated otherwise in a credit line to the material. If material is not included in the article's Creative Commons licence and your intended use is not permitted by statutory regulation or exceeds the permitted use, you will need to obtain permission directly from the copyright holder. To view a copy of this licence, visit http://creativecommons.org/licenses/by/4.0/.

\section{References}

Amin, M. H., Mohamed, E. K. A., \& Elragal, A. (2021). CSR disclosure on Twitter: Evidence from the UK. International Journal of Accounting Information Systems, 40, 100500.

Balasubramanian, S. K., Fang, Y., \& Yang, Z. (2020). Twitter presence and experience improve corporate social responsibility outcomes. Journal of Business Ethics, 1-21.
Bangsa, A. B., \& Schlegelmilch, B. B. (2020). Linking sustainable product attributes and consumer decision-making: Insights from a systematic review. Journal of Cleaner Production, 245, 118902.

Ben-Amar, W., Chang, M., \& McIlkenny, P. (2017). Board gender diversity and corporate response to sustainability initiatives: Evidence from the carbon disclosure project. Journal of Business Ethics, 142(2), 369-383.

Benitez, J., Ruiz, L., Castillo, A., \& Llorens, J. (2020). How corporate social responsibility activities influence employer reputation: The role of social media capability. Decision Support Systems, 129, 113223.

Braojos-Gomez, J., Benitez-Amado, J., \& Llorens-Montes, F. J. (2015). How do small firms learn to develop a social media competence? International Journal of Information Management, 35(4), 443-458.

Chae, B. K., \& Park, E. O. (2018). Corporate social responsibility (CSR): A survey of topics and trends using Twitter data and topic modeling. Sustainability, 10(7), 2231.

Chahine, S., \& Malhotra, N. K. (2018). Impact of social media strategies on stock price: the case of Twitter. European Journal of Marketing.

Chen, H., De, P., \& Hu, Y. J. (2015). IT-enabled broadcasting in social media: An empirical study of artists' activities and music sales. Information Systems Research, 26(3), 513-531.

Choi, T.-M., Cheng, T. C. E., \& Zhao, X. (2016). Multi-methodological research in operations management. Production and Operations Management, 25(3), 379-389.

Chung, S., Animesh, A., Han, K., \& Pinsonneault, A. (2020a). Financial returns to firms' communication actions on firm-initiated social media: Evidence from Facebook business pages. Information Systems Research, 31(1), 258-285.

Chung, A., Woo, H., \& Lee, K. (2020b). Understanding the information diffusion of tweets of a non-profit organization that targets female audiences: an examination of Women Who Code's tweets. Journal of Communication Management.

Corbett, C. J., \& DeCroix, G. A. (2001). Shared-savings contracts for indirect materials in supply chains: Channel profits and environmental impacts. Management Science, 47(7), 881-893.

Corcione, A. (2020). What Is Greenwashing? Businessnewsdaily. Com. https://www.businessnewsdaily.com/10946-greenwashing. html. Accessed 20 Oct 2021

da Silva Faia, V., \& Vieira, V. A. (2018). Two-way and Three-way Moderating Effects in Regression Analysis and Interactive Plots. Brazilian Journal of Management/Revista de Administração Da UFSM, 11(4).

Deng, S., Huang, Z. J., Sinha, A. P., \& Zhao, H. (2018). The interaction between microblog sentiment and stock return: An empirical examination. MIS Quarterly, 42(3), 895-918.

Di Gangi, P. M., Johnston, A. C., Worrell, J. L., \& Thompson, S. C. (2018). What could possibly go wrong? A multi-panel Delphi study of organizational social media risk. Information Systems Frontiers, 20(5), 1097-1116.

Esfahbodi, A., Zhang, Y., \& Watson, G. (2016). Sustainable supply chain management in emerging economies: Trade-offs between environmental and cost performance. International Journal of Production Economics, 181, 350-366.

Ferreira, P., Telang, R., \& De Matos, M. G. (2019). Effect of Friends' Churn on Consumer Behavior in Mobile Networks. Journal of Management Information Systems, 36(2), 355-390.

Fischer, D., Lüdecke, G., Godemann, J., Michelsen, G., Newig, J., Rieckmann, M., \& Schulz, D. (2016). Sustainability communication. In Sustainability Science, 139-148. Springer.

Foltean, F. S., Trif, S. M., \& Tuleu, D. L. (2019). Customer relationship management capabilities and social media technology use: Consequences on firm performance. Journal of Business Research, 104, 563-575.

Fox, G. L., Rinaldo, S. B., \& Amant, K. S. (2015). The Effects of Rhetorical Figures and Cognitive Load in Word-of-Mouth Communications. Psychology \& Marketing, 32(10), 1017-1030. 
Fraustino, J. D., \& Connolly-Ahern, C. (2015). Corporate associations written on the wall: Publics' responses to Fortune 500 ability and social responsibility Facebook posts. Journal of Public Relations Research, 27(5), 452-474.

Fuchs, C., Prandelli, E., \& Schreier, M. (2010). The psychological effects of empowerment strategies on consumers' product demand. Journal of Marketing, 74(1), 65-79.

Ghosh, D., \& Shah, J. (2012). A comparative analysis of greening policies across supply chain structures. International Journal of Production Economics, 135(2), 568-583.

Ghosh, I., \& Sanyal, M. K. (2021). Introspecting predictability of market fear in Indian context during COVID-19 pandemic: An integrated approach of applied predictive modelling and explainable AI. International Journal of Information Management Data Insights, 1(2), 100039.

Gómez-Carrasco, P., \& Guillamón-Saorl’lin, E., \& Garcia Osma, B. (2021). Stakeholders versus firm communication in social media: The case of Twitter and corporate social responsibility information. European Accounting Review, 30(1), 31-62.

Gomez, M., Lopez, C., \& Molina, A. (2019). An integrated model of social media brand engagement. Computers in Human Behavior, 96, 196-206.

Grover, P., Kar, A. K., Gupta, S., \& Modgil, S. (2021). Influence of political leaders on sustainable development goals - insights from twitter. Journal of Enterprise Information Management, 34(6), 1893-1916.

Grover, P., Kar, A. K., \& Ilavarasan, P. V. (2019). Impact of corporate social responsibility on reputation-Insights from tweets on sustainable development goals by CEOs. International Journal of Information Management, 48, 39-52.

Hawn, O., Chatterji, A. K., \& Mitchell, W. (2018). Do investors actually value sustainability? New evidence from investor reactions to the Dow Jones Sustainability Index (DJSI). Strategic Management Journal, 39(4), 949-976.

Heggestuen, J., \& Danova, T. (2013). Brand presence: How to choose where to be on social media, without breaking your budget. Business Insider. http://www.businessinsider.com/top-social-mediabrand-strat egies-2. Accessed 20 Oct 2021

Herzig, C., \& Schaltegger, S. (2006). Corporate sustainability reporting. An overview. In Sustainability accounting and reporting (pp. 301-324). Springer.

Hewett, K., Rand, W., Rust, R. T., \& Van Heerde, H. J. (2016). Brand buzz in the echoverse. Journal of Marketing, 80(3), 1-24.

Hu, Y., Xu, A., Hong, Y., Gal, D., Sinha, V., \& Akkiraju, R. (2019). Generating business intelligence through social media analytics: Measuring brand personality with consumer-, employee-, and firm-generated content. Journal of Management Information Systems, 36(3), 893-930.

Huang, L., Clarke, A., Heldsinger, N., \& Tian, W. (2019). The communication role of social media in social marketing: A study of the community sustainability knowledge dissemination on LinkedIn and Twitter. Journal of Marketing Analytics, 7(2), 64-75.

Jha, A. K., \& Shah, S. (2021). Disconfirmation effect on online review credibility: An experimental analysis. Decision Support Systems, $145,113519$.

Jha, A. K., \& Shah, S. (2019). Social Influence on Future Review Sentiments: An Appraisal-Theoretic View. Journal of Management Information Systems, 36(2), 610-638.

Kapoor, N., Ahmad, N., Nayak, S. K., Singh, S. P., Ilavarasan, P. V., \& Ramamoorthy, P. (2021). Identifying infrastructural gap areas for smart and sustainable tribal village development: A data science approach from India. International Journal of Information Management Data Insights, 1(2), 100041.

Kar, A. K. (2020). What affects usage satisfaction in mobile payments? Modelling user generated content to develop the "digital service usage satisfaction model." Information Systems Frontiers, Forthcomin, Information Systems Frontiers, 1-21.

Kim, E. H., \& Lyon, T. P. (2015). Greenwash vs. brownwash: Exaggeration and undue modesty in corporate sustainability disclosure. Organization Science, 26(3), 705-723.

Kim, S. J., Maslowska, E., \& Tamaddoni, A. (2019). The paradox of (dis) trust in sponsorship disclosure: The characteristics and effects of sponsored online consumer reviews. Decision Support Systems, 116, 114-124.

Kong, H. M., Witmaier, A., \& Ko, E. (2021). Sustainability and social media communication: How consumers respond to marketing efforts of luxury and non-luxury fashion brands. Journal of Business Research, 131, 640-651.

Kumar, S., Kar, A. K., \& Ilavarasan, P. V. (2021). Applications of text mining in services management: A systematic literature review. International Journal of Information Management Data Insights, 1(1), 100008 .

Kushwaha, A. K., Kar, A. K., \& Dwivedi, Y. K. (2021). Applications of big data in emerging management disciplines: A literature review using text mining. International Journal of Information Management Data Insights, 1(2), 100017.

Kushwaha A. K., Mandal S., Pharswan R., Kar A. K., Ilavarasan P. V. (2020a) Studying Online Political Behaviours as Rituals: A Study of Social Media Behaviour Regarding the CAA. In: Sharma S.K., Dwivedi Y.K., Metri B., Rana N.P. (eds) Re-imagining Diffusion and Adoption of Information Technology and Systems: A Continuing Conversation. TDIT. IFIP Advances in Information and Communication Technology, 618. Springer, Cham. https://doi.org/ 10.1007/978-3-030-64861-9_28

Kushwaha A. K., Kar A. K., Ilavarasan P. V. (2020b) Predicting Information Diffusion on Twitter a Deep Learning Neural Network Model Using Custom Weighted Word Features. In: Hattingh M., Matthee M., Smuts H., Pappas I., Dwivedi Y., Mäntymäki M. (eds) Responsible Design, Implementation and Use of Information and Communication Technology. I3E. Lecture Notes in Computer Science, 12066. Springer, Cham. https://doi.org/10.1007/978-3030-44999-5_38

Kushwaha A. K., Kar A. K. (2020c) Language Model-Driven Chatbot for Business to Address Marketing and Selection of Products. In: Sharma S.K., Dwivedi Y.K., Metri B., Rana N.P. (eds) Reimagining Diffusion and Adoption of Information Technology and Systems: A Continuing Conversation. TDIT 2020. IFIP Advances in Information and Communication Technology, 617. Springer, Cham. https://doi.org/10.1007/978-3-030-64849-7_3

Lee, E., \& Staelin, R. (1997). Vertical strategic interaction: Implications for channel pricing strategy. Marketing Science, 16(3), 185-207.

Lee, K., Oh, W.-Y., \& Kim, N. (2013). Social media for socially responsible firms: Analysis of Fortune 500's Twitter profiles and their CSR/CSIR ratings. Journal of Business Ethics, 118(4), 791-806.

Luo, X., Zhang, J., \& Duan, W. (2013). Social media and firm equity value. Information Systems Research, 24(1), 146-163.

Lyon, T. P., \& Montgomery, A. W. (2013). Tweetjacked: The impact of social media on corporate greenwash. Journal of Business Ethics, 118(4), 747-757.

Manetti, G., \& Bellucci, M. (2016). The use of social media for engaging stakeholders in sustainability reporting. Accounting, Auditing \& Accountability Journal.

Metaxas, P. T., Mustafaraj, E., Wong, K., Zeng, L., O’Keefe, M., \& Finn, S. (2015). What Do Retweets Indicate? Results from User Survey and Meta-Review of Research. ICWSM, 658-661.

Minton, E., Lee, C., Orth, U., Kim, C.-H., \& Kahle, L. (2012). Sustainable marketing and social media: A cross-country analysis of motives for sustainable behaviors. Journal of Advertising, 41(4), 69-84. 
Naciti, V. (2019). Corporate governance and board of directors: The effect of a board composition on firm sustainability performance. Journal of Cleaner Production, 237(117727).

O’Reilly, T., \& Milstein, S. (2011). The twitter book (2nd ed.). O'Reilly Media, Inc.

Orth, U. R., \& Green, M. T. (2009). Consumer loyalty to family versus non-family business: The roles of store image, trust and satisfaction. Journal of Retailing and Consumer Services, 16(4), 248-259.

Pew Research Centre. (2021). News Use Across Social Media Platforms in 2020. https://www.journalism.org/2021/01/12/news-useacross-social-media-platforms-in-2020/. Accessed 20 Oct 2021

Porter, M. E., \& der Linde, C. (2011). Green and competitive-ending the stalemate.

Raj, A., Biswas, I., \& Srivastava, S. K. (2018). Designing supply contracts for the sustainable supply chain using game theory. Journal of Cleaner Production, 185, 275-284.

Reilly, A. H., \& Hynan, K. A. (2014). Corporate communication, sustainability, and social media: It's not easy (really) being green. Business Horizons, 57(6), 747-758.

Richardson, J., Grose, J., Nelmes, P., Parra, G., \& Linares, M. (2016). Tweet if you want to be sustainable: A thematic analysis of a Twitter chat to discuss sustainability in nurse education. Journal of Advanced Nursing, 72(5), 1086-1096.

RobecoSAM. (2020). Dow Jones Sustainability Indices: DJSI index family. Robecosam.Com. https://www.robecosam.com/csa/indices/djsiindex-family.html. Accessed 20 Oct 2021

Robinson, M., Kleffner, A., \& Bertels, S. (2011). Signaling sustainability leadership: Empirical evidence of the value of DJSI membership. Journal of Business Ethics, 101(3), 493-505.

Roth, A., \& Rosenzweig, E. (2020). Advancing Empirical Science in Operations Management Research: A Clarion Call to Action. Manufacturing \& Service Operations Management.

Savaskan, R. C., Bhattacharya, S., \& Van Wassenhove, L. N. (2004). Closed-loop supply chain models with product remanufacturing. Management Science, 50(2), 239-252.

Saxton, G. D., Gómez, L., Ngoh, Z., Lin, Y.-P., \& Dietrich, S. (2019). Do CSR messages resonate? Examining public reactions to firms' CSR efforts on social media. Journal of Business Ethics, 155(2), 359-377.

Schetgen, L., Bogaert, M., \& Van den Poel, D. (2020). Predicting donation behavior: Acquisition modeling in the nonprofit sector using Facebook data. Decision Support Systems, Forthcomin, 113446.

Schmidt, C. G., Wuttke, D. A., Ball, G. P., \& Heese, H. S. (2020). Does social media elevate supply chain importance? An empirical examination of supply chain glitches, Twitter reactions, and stock market returns. Journal of Operations Management.

Segran, E. (2019). H\&M, Zara, and other fashion brands are tricking shoppers with vague sustainability claims. Fastcompany.Com. https:// www.fastcompany.com/90385370/hm-zara-and-other-fashion-brandsare-tricking-consumers-with-vague-sustainability-claims. Accessed 20 Oct 2021

Shooster, J. (2020). In Court, "Sustainable” Brands Argue that Marketing Claims are Meaningless. Sentinent Media. https://sentientmedia.org/incourt-sustainable-brands-argue-that-marketing-claims-are-meaningless/

Sul, H. K., Dennis, A. R., \& Yuan, L. (2017). Trading on twitter: Using social media sentiment to predict stock returns. Decision Sciences, 48(3), 454-488.

Tassios, C. (2020). Insta-gloss: Cosmetics retailer Mecca called out over 'cruelty-free' claims on social media. Smartcompany.Com. Au. https://www.smartcompany.com.au/industries/retail/meccainstagram-cruelty-free-cosmetics/. Accessed 20 Oct 2021

Tsay, A. A., \& Agrawal, N. (2000). Channel dynamics under price and service competition. Manufacturing \& Service Operations Management, 2(4), 372-391.
Tung, W. F., \& Jordann, G. (2017). Crowdsourcing social network service for social enterprise innovation. Information Systems Frontiers, 19(6), 1311-1327.

Valentine, O. (2019). Social Media's Influence on Green Consumerism. WearSocial.Com. https://wearesocial.com/blog/2019/11/socialmedias-influence-on-green-consumerism. Accessed 20 Oct 2021

Voorveld, H. A. M. (2019). Brand communication in social media: A research agenda. Journal of Advertising, 48(1), 14-26.

Wu, Y., Ngai, E. W., Wu, P., \& Wu, C. (2020). Fake online reviews: Literature review, synthesis, and directions for future research. Decision Support Systems, Fothcoming, 113280.

Xie, K., \& Lee, Y.-J. (2015). Social media and brand purchase: Quantifying the effects of exposures to earned and owned social media activities in a two-stage decision making model. Journal of Management Information Systems, 32(2), 204-238.

Yadav, H., Kar, A.K., \& Kashiramka, S. (2021). How does entrepreneurial orientation and SDG orientation of CEOs evolve before and during a pandemic. Journal of Enterprise Information Management, Forthcoming.

Yenipazarli, A. (2017). To collaborate or not to collaborate: Prompting upstream eco-efficient innovation in a supply chain. European Journal of Operational Research, 260(2), 571-587.

Yoo, E., Rabinovich, E., \& Gu, B. (2020). The growth of follower networks on social media platforms for humanitarian operations. Production and Operations Management, 29(12), 2696-2715.

Yu, Y., Duan, W., \& Cao, Q. (2013). The impact of social and conventional media on firm equity value: A sentiment analysis approach. Decision Support Systems, 55(4), 919-926.

Zhang, M., Jansen, B. J., \& Chowdhury, A. (2011). Business engagement on Twitter: A path analysis. Electronic Markets, 21(3), 161.

Zhu, W., \& He, Y. (2017). Green product design in supply chains under competition. European Journal of Operational Research, 258(1), 165-180.

Publisher's Note Springer Nature remains neutral with regard to jurisdictional claims in published maps and institutional affiliations.

Ashish Kumar Jha is an Associate Professor in the field of Business Analytics at Trinity Business School. His research revolves around the areas of technology innovation and social media analysis. Ashish uses statistical and analytical techniques to understand how firms and consumers interact on social platforms and its effects for both firms and their consumers. He holds a PhD in the field of Management Information Systems. His papers have been published in journals such as Journal of Management Information Systems, Information \& Management, Decision Support Systems, International Journal of Production Economics, Information Systems Frontiers, Communications of AISamong others. Ashish has been a part of research groups working on robotic process automation in IT services industry and has co-invented patented robotic process automation systems.

Nishant K. Verma is an Assistant Professor in the field of Operations Management at Indian Institute of Management Bangalore (IIMB). He holds a PhD in the field of Operations Management. His research interests include flexibility issues in supply chains, product modularity issues, signalling mechanisms in operations management, and sustainability issues in operations management. He has published his works in European Journal of Operational Research and Computers \& Industrial Engineering, and has been a reviewer at Decision Support Systems (DSS) and European Journal of Operational Research (EJOR). 